\title{
ANTIVIRALE PHOTODYNAMISCHE THERAPIE BEI COVID-19
}

\section{Liebe Kolleginnen und Kollegen,}

die Corona-Pandemie hält seit einem Jahr die Welt im Würgegriff und ein Ende ist noch nicht abzusehen. Ganz im Gegenteil stehen wir bei den neu aufgetretenen $\mathrm{Mu}-$ tationen am Beginn einer dritten Welle. Es ist gut, dass die Impfungen bereits begonnen haben und wir brauchen diese natürlich zur langfristigen Prävention und Eindämmung der Infektionen. Aber immer noch haben wir keine wirksame Therapie. Es laufen derzeit etliche Studien mit vielversprechenden Medikamenten, aber noch ist kein wirksames in Sicht. Im Prinzip verfuigen wir praktisch über keine viruziden Medikamente, wir haben noch nicht einmal ein wirksames Mittel gegen Schnupfen oder Grippe entwickeln können. Bei Grippe wird immer gern auf die Impfung verwiesen, aber bedingt durch die ständigen $\mathrm{Mu}-$ tationen muss der Impfstoff jährlich angepasst werden. So waren trotz Impfung im Winter 2017/2018 allein in Deutschland durch Influenza und deren Folgen 25.100 Todesfalle zu beklagen und weltweit geschätzt 645.000. Dies ist eine gewaltige $\mathrm{Zahl}$ in Anbetracht der verfügbaren Vaccine. Betrachtet man die Effektivität der Influenzaimpfung, so lag sie in 2017/2018 bei 15\% und in den 4 Jahren davor bei ca. 20\%. Wir müssen uns darauf einstellen, dass die Situation bei COVID-19 ähnlich verlaufen könnte und nach Anpassung der Impfungen bereits die nächsten Anpassungen erfolgen müssen, was immer wieder Monate Zeit kosten wird. So ist eine Therapie neben der Impfprävention notwendiger denn je. Wir wissen aus Erfahrung, dass die Grippewelle jährlich spätestens im April abebbt, wobei die zunehmende UV-Strahlung sicher ein wichtiger Faktor ist. Die desinfizierende bzw. sterilisierende Wirkung von UV-Licht ist ja hinlänglich bekannt. Allerdings ist die Wirkung des natürlichen UV-Lichtes beim COVID19-Virus offensichtlich nicht ausreichend, was man an der Ausbreitung auch in warmen Ländern mit hoher Sonnen- einstrahlung wie z.B. Brasilien oder Indien gesehen hat. ZurWirkungsverstärkung benötigen wir eine photodynamisch aktive Substanz, die sich an das Virus bindet und es sensibel gegen bestimmte Wellenlängen des Lichtes machen, die dem Absorptionsspektrum der lichtsensiblen Substanz (Photosensitizer) entsprechen. Man nennt diese Methode antivirale photodynamische Therapie (aPDT). Sehr gut dokumentiert ist das Riboflavin (Vitamin B2), das sich in wenigen Minuten an die virale RNA bindet und durch Aktivierung mit UVA- und Blaulicht die Nukleinsäureketten rupturieren lässt. Vitamin B2 kann eingenommen werden und sich nach Resorption rasch an Viren in der Blutbahn binden. Dies ist wichtig, da wir heute viel mehr über die systemischen Wirkungen desVirus auf Leber, Niere, Herz, Gehirn wissen. Riboflavin kann nach Auflösen in Wasser in Mund und Nase gesprüht werden und bindet sich rasch an oberflächliche Viren in der Schleimhaut. Die anschließende Bestrahlung erfolgt einerseits am Handgelenk mit der Laseruhr zur nichtinvasiven Blutbestrahlung und lokal im Mund und in der Nase mit spezifischen Adaptern, die mit blauen und ultravioletten-A-Dioden bestückt sind. Eine erste Pilotstudie an 20 COVID-19-Patienten wurde im November 2020 in Teheran durchgeführt. Die Ergebnisse waren klinisch und laborchemisch sehr erfolgreich. Alle Patienten waren nach wenigen Tagen deutlich gebessert, was sich auch an der Viruslast im Abstrich nachweisen ließ. Eine Kontrollgruppe mit 20 Patienten ohne Behandlung zeigte keineVerbesserungen. In der Zwischenzeit wurden weitere 100 Patienten untersucht mit ähnlich guten Ergebnissen. Eine Kurzfassung der ersten Studie finden Sie in diesem Heft. Die beschriebene Therapiemethode dürfte auch bei weiteren respiratorischen Virusinfekten wirksam sein und besonders auch unabhängig von derzeitigen und künftigen Mutationen.

M. Weber

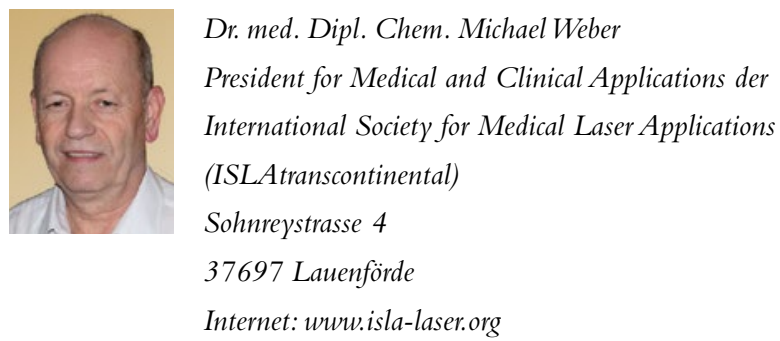

